\title{
Determination of 4-Methylimidazole in Ammonia Caramel Using Gas Chromatography-Tandem Mass Spectrometry (GC-MS/MS)
}

\author{
Martyna N. Wieczorek $\left(\mathbb{D},{ }^{1}\right.$ Krzysztof Przygoński ${ }^{D},{ }^{2}$ and Henryk H. Jeleń ${ }^{1}{ }^{1}$ \\ ${ }^{1}$ Faculty of Food Science and Nutrition, Poznań University of Life Sciences, Wojska Polskiego 31, 60-624 Poznań, Poland \\ ${ }^{2}$ Department of Food Concentrates and Starch Products, Institute of Agricultural and Food Biotechnology, Starotęcka 40, \\ 61-361 Poznań, Poland
}

Correspondence should be addressed to Henryk H. Jeleń; henrykj@up.poznan.pl

Received 30 October 2017; Revised 31 January 2018; Accepted 11 February 2018; Published 29 March 2018

Academic Editor: Antimo Di Maro

Copyright (C) 2018 Martyna N. Wieczorek et al. This is an open access article distributed under the Creative Commons Attribution License, which permits unrestricted use, distribution, and reproduction in any medium, provided the original work is properly cited.

\begin{abstract}
One of Maillard reaction products formed in the production of ammonia caramel is 4(5)-methylimidazole (4-MeI) classified as carcinogen. A method of 4-MeI determination based on ion-pair extraction and derivatisation with isobutyl chloroformate with subsequent gas chromatography-tandem mass spectrometry analysis was proposed. Tandem mass spectrometry was applied to reduce the influence of matrix and increase the selectivity and sensitivity of the method. Triple quadrupole GC-MS system was used for this study. The collision energies were optimized for MRM mode. The detection (LOD) and quantification limits (LOQ) of the elaborated method were 17 and $37.8 \mu \mathrm{g} \mathrm{kg}^{-1}$, respectively, repeatability was $<15 \%$ RSD for analyzed caramel samples, and the recovery for $4-\mathrm{MeI}$ was $101 \%$. Comparison of MS/MS with SIM detection on the same instrument proved almost 30 times lower LODs achieved by tandem mass spectrometry compared to SIM. Described method can be routinely used for monitoring 4-MeI as a quality and safety marker in the production of ammonia caramel.
\end{abstract}

\section{Introduction}

Caramel is one of the worldwide most popular food colorants, labeled with the symbols E150a: caustic caramel, E150b: caustic sulfite caramel, E150c: ammonia caramel, and E150d: sulfite ammonia caramel. It is added for variety of foods and beverages, such as sauces, wines, beers, desserts, confectionary products, cola beverages, and baked goods [1]. One of many heterocyclic processing compounds formed in the production of ammonia caramel is 4(5)-methylimidazole (4-MeI), which is a product of Maillard reaction. At neutral to basic $\mathrm{pH}$ solutions there are two tautomers: 4methylimidazole and 5-methylimidazole exist in equilibrium [2]. Methylglyoxal was proposed as the starting precursor in 4-MeI formation (Figure 1). In 2007 the National Toxicology Program (NTP) stated 4-methylimidazole as a cancer causing chemical and in 2011 the State of California also specified 4-methylimidazole in Proposition 65 as a carcinogen. The level of 4-MeI, which is deemed to pose no significant risk, is $29 \mu \mathrm{g} /$ day [2].

The caramel matrix is very complex and it contains high number and amount of different compounds formed during caramelization process. One of those numerous components is 4-MeI. Its chemical properties, especially high polarity and basic character, make 4-MeI extraction and purification challenging steps. So far, analysis of this compound by GC/MS method was performed after ion pair extraction combined with derivatization process and this technique seemed to be the most effective one; however some recent studies showed the possibility of $4-\mathrm{MeI}$ analysis by solid phase microextraction (SPME) method without derivatization [4]. Bis(2-ethylhexyl) phosphoric acid (BEHPA) is an ion pairing compound used in extraction of basic compounds and alkyl chloroformates (such as isobutyl chloroformate, IBCF) proved be a good derivatization reagents providing formation of $\mathrm{N}$-alkoxycarbonyl 


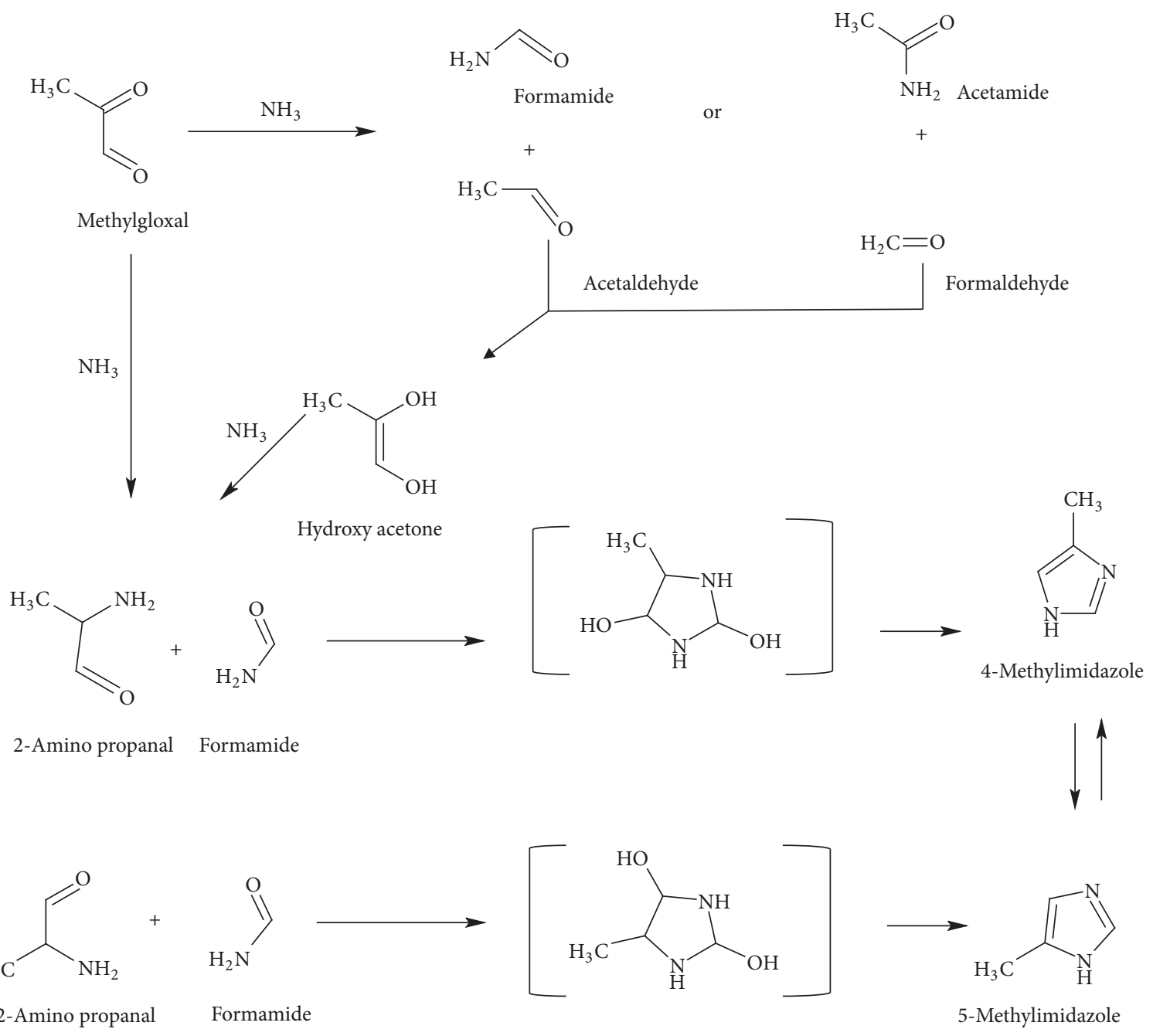

Figure 1: Proposed formation mechanisms of 4(5)-methylimidazole from methylglyoxal (adapted with permission from Moon and Shibamoto 2011 [3], Copyright (2011), American Chemical Society).

esters [5]. The Codex Alimentarius of the World Health Organization has established maximum concentration of 4MeI in caramels III and IV, which is $250 \mathrm{mg} \mathrm{kg}^{-1}$ on an equivalent colour basis. It caused the necessity of developing and improving analytical extraction techniques, allowing for reliable detection of 4-MeI level in food and food additives matrices [6]. Described method of extraction was successfully applied for determination of $4-\mathrm{MeI}$ in coffee [7]. Cunha et al. [8] used it to extract 4-MeI from soy and balsamic sauces and Karim and Smith [9] applied this procedure to determine the amount of 4 -MeI in cooked meat.

The aim of this study was to develop a reliable and fast quantitation technique allowing for determination of 4-MeI in ammonia caramel produced on the pilot/industrial scale. The novelty of the study was to utilize the selectivity of tandem mass spectrometry for the qualitative and quantitative analysis, whereas usually GC-MS in SIM mode was used for 4-MeI analysis. By eliminating matrix influence in MS/MS (MRM) lower detection limits can be achieved.

\section{Materials and Methods}

2.1. Materials and Chemicals. Ammonia caramel (E150c) was produced in a pilot scale at the Institute of Agricultural and Food Biotechnology, Department of Food Concentrates and Starch Products, in Poznań.

4-methylimidazole (4-MeI), 2-ethylimidazole (2-EI), bis(2-ethylhexyl) phosphoric acid (BEHPA), isobutyl chloroformate (IBCF), hydrochloric acid, isooctane, and pyridine were obtained from Sigma-Aldrich, Poznań, Poland.

2.2. Sample Preparation and GC/MS Analysis. 4-Methylimidazole was extracted from caramel sample using methodology described earlier by Fernandes and Ferreira [5] and later by Cunha et al. [10]. The developed method is based on ion pair extraction with bis(2-ethylhexyl) phosphate (BEHPA) and derivatization with isobutyl chloroformate (IBCF). The stock solutions of $4-\mathrm{MeI}\left(100 \mathrm{mg} \mathrm{L}^{-1}\right)$ and the internal standard (2-EI, $\left.1 \mathrm{~g} \mathrm{~L}^{-1}\right)$ were prepared by dissolving the compounds in $0.1 \mathrm{~mol} \mathrm{~L}^{-1} \mathrm{HCl}$. 
The calibration curve was prepared by spiking caramel solution to compensate for matrix effect, with 4-MeI standard to obtain six concentrations: $0 \mu \mathrm{g} \mathrm{m}^{-1}, 2 \mu \mathrm{g} \mathrm{mL}^{-1}$, $4 \mu \mathrm{g} \mathrm{mL}^{-1}, 10 \mu \mathrm{g} \mathrm{mL}^{-1}, 20 \mu \mathrm{g} \mathrm{mL}^{-1}$, and $40 \mu \mathrm{g} \mathrm{mL}^{-1}$. Internal standard (2-EI) was added to all calibration solutions and to analyzed samples. Then, the analyte was extracted by ion pair extraction and derivatized according to described procedure. Extraction was done in triplicate for every concentration level. Additionally the calibration solutions were injected before the caramels analysis to check the repeatability.

2.2.1. Ion Pair Extraction. 3 grams of ammonia caramel was weighed and diluted with $10 \mathrm{~mL}$ of phosphate buffer and then potassium hydroxide was titrated to reach $\mathrm{pH}$ 6.0. Next, the whole mixture was transferred to $25 \mathrm{~mL}$ flask and filled up to $25 \mathrm{~mL}$ with water. $1 \mathrm{~mL}$ from this solution was transferred to the second vial and extracted with $2 \mathrm{~mL} 0.1 \mathrm{M}$ bis(2-ethylhexyl) phosphoric acid (BEHPA) in chloroform. The mixture was mixed for $10 \mathrm{~min}$. After centrifugation at $1500 \mathrm{~g}$ for $10 \mathrm{~min}$, the bottom layer $(1.8 \mathrm{~mL})$ was transferred to the third tube and then backextracted with $1.5 \mathrm{~mL} \mathrm{HCl}$. After centrifugation the upper layer was ready for derivatization.

2.2.2. Derivatization. A $500 \mu \mathrm{L}$ aliquot of aqueous phase was mixed with equal amount $(500 \mu \mathrm{L})$ of acetonitrile: isobutanol:pyridine $(5: 3: 2 \mathrm{v} / \mathrm{v})$ and $60 \mu \mathrm{L}$ isobutyl chloroformate (IBCF). After $10 \mathrm{~s}$ of hand-shaking, $1 \mathrm{~mL}$ of saturated $\mathrm{NaHCO}_{3}$ was added and sample was vortexed for $1 \mathrm{~min}$. Afterwards, $1 \mathrm{~mL}$ of isooctane was added and sample was stirred for $10 \mathrm{~min}$. Upon centrifugation the upper layer was ready for GC-MS/MS analysis.

2.3. Gas Chromatography-Tandem Mass Spectrometry. GCMS/MS analysis was carried out on gas chromatograph coupled with triple quadrupole mass spectrometer (7890A/7000B, Agilent Technologies, Santa Clara, CA). Samples were injected in a splitless mode onto RTX-5MS column $(10 \mathrm{~m} \times 0.18 \mathrm{~mm} \times 0.1 \mathrm{um}$, Restek, Bellefonte, PA). The column oven temperature program during analysis was as follows: the initial temperature was from $70^{\circ} \mathrm{C}$ and maintained for $1 \mathrm{~min}$, with temperature rise at a rate of $20^{\circ} \mathrm{C} \mathrm{min}^{-1}$, to $280^{\circ} \mathrm{C}$. Temperatures of injector and mass spectrometer ion source were $280^{\circ} \mathrm{C}$ and $230^{\circ} \mathrm{C}$, respectively. Both the analyzed compound and the internal standard were analyzed first in scan mode, then in SIM, and finally in MS/MS. The determination of product ions was accomplished in product ion mode, their origin checked in precursor ion mode, and multiple reaction monitoring (MRM) was used for quantitative purposes. The carrier gas was helium and the flow rate was $1 \mathrm{~mL} \mathrm{~min}{ }^{-1}$. Nitrogen was used as the collision gas and its flow was set to $1.5 \mathrm{~mL} \mathrm{~min}^{-1}$, resulting in the highest areas of product ions. Collision energies tested varied from 5 to $50 \mathrm{~V}$, which resulted in product ions of different intensities. The optimal collision induced dissociation (CID) value occurred at $10 \mathrm{~V}$. In this process product ion spectra with a minimal precursor ion abundances and maximal of selected product ions were chosen for further method development. The mass spectrometer was operated in electron ionization (EI) mode

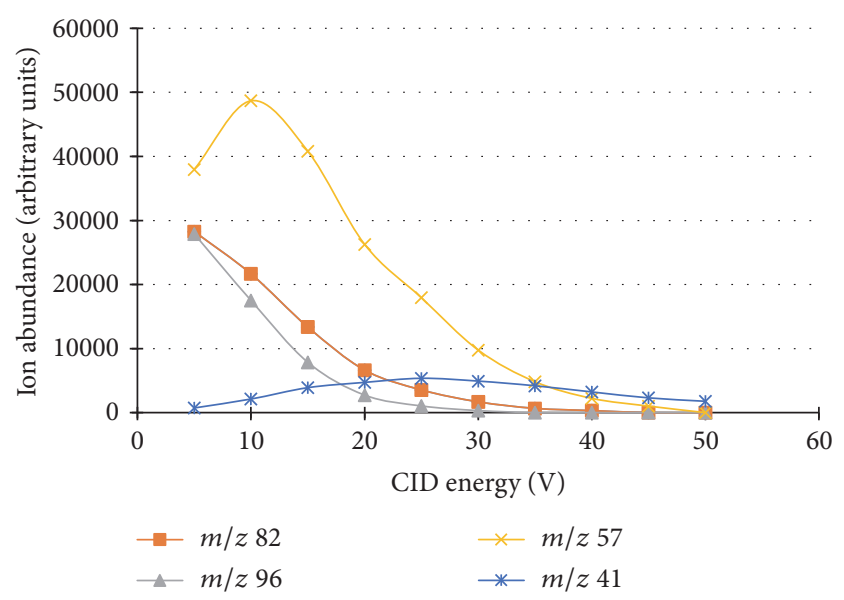

FIGURE 2: Effect of collision cell RF voltage (in a range of 10-50 V) on relative ion transfer efficiency of ions of different masses.

at $70 \mathrm{eV}$. Precursor ions used for MRM quantitative method were $m / z 182$ for 4 -MeI and $m / z 196$ for 2-EI (internal standard). Precursor ions of both compounds were subjected to secondary fragmentation by which the resulting product ions were $\mathrm{m} / z 82$ for 4 -MeI and $\mathrm{m} / z 96$ for 2-EI. Data acquisition and analyses were performed using the Agilent Technologies MassHunter Workstation software.

\section{Result and Discussion}

3.1. Gas Chromatography and Tandem Mass Spectrometry. In the present work the GC-MS/MS method was chosen to compensate for the complex matrix of Maillard reaction products that are formed in caramel production process. The selectivity was obtained by selective sample preparation involving specific extraction process and selective detection by MS/MS. The first step of the MS/MS optimization was the choice of the most selective and abundant precursor ion for 4 -MeI derivative. The parent ion at $m / z 182$ was selected as the precursor ion for MS/MS analysis and $m / z 82$ as product ion. The $m / z 82$ ion was evaluated as the most specific one because $82 \mathrm{Da}$ is the molecular mass of 4 -methylimidazole. The intensity of $m / z$ formed from fragmentation of $m / z 182$ was monitored in product ions mode using different CID energies (voltages) in a range of $5-50 \mathrm{~V} .10 \mathrm{~V}$ was chosen for subsequent analyses as minimal abundance was obtained of ion $m / z 182$ with highly abundant product $-m / z 82$. Similarly, $m / z 96$ was used as a product of $m / z 196$ to be monitored in internal standard (4-EI), also indicating a molecular weight ion of this compound. The monitoring of most abundant product ions in $4-\mathrm{MeI}$ and $4-\mathrm{EI}$ is shown on Figure 2.

Linearity of the method was evaluated in the concentration range up to $40 \mathrm{mg} \mathrm{L}^{-1}\left(\mu \mathrm{g} \mathrm{mL}^{-1}\right)$. The concentration range was dependent on the expected concentration of 4$\mathrm{MeI}$ in ammonium caramel. The coefficient of determination $\left(R^{2}\right)$ was 0.99 . The repeatability of the method when caramel samples were analyzed was satisfactory providing relative standard deviation values (RSD \%) for samples run 


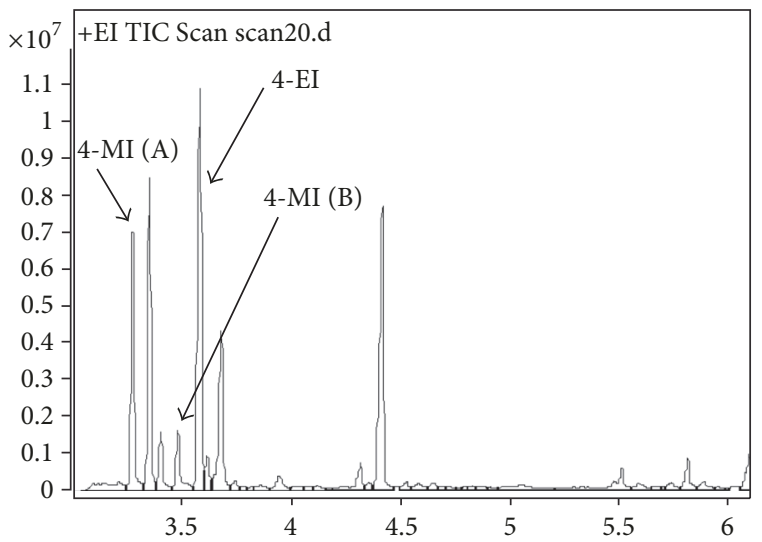

(a)

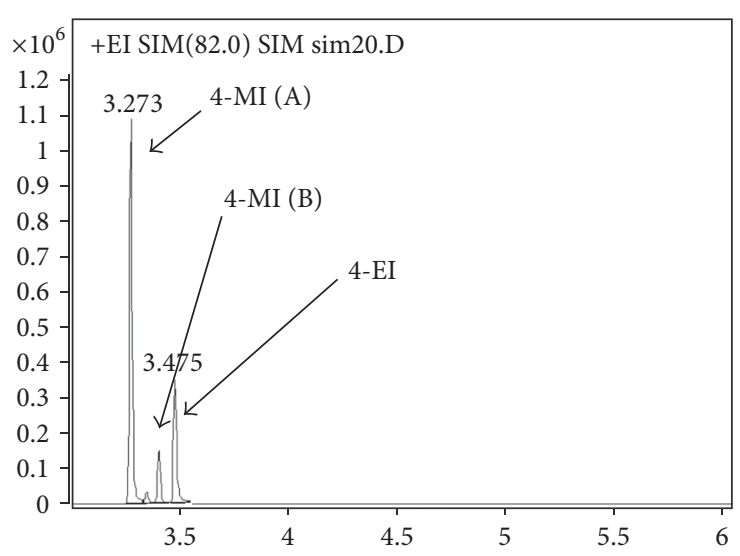

(b)

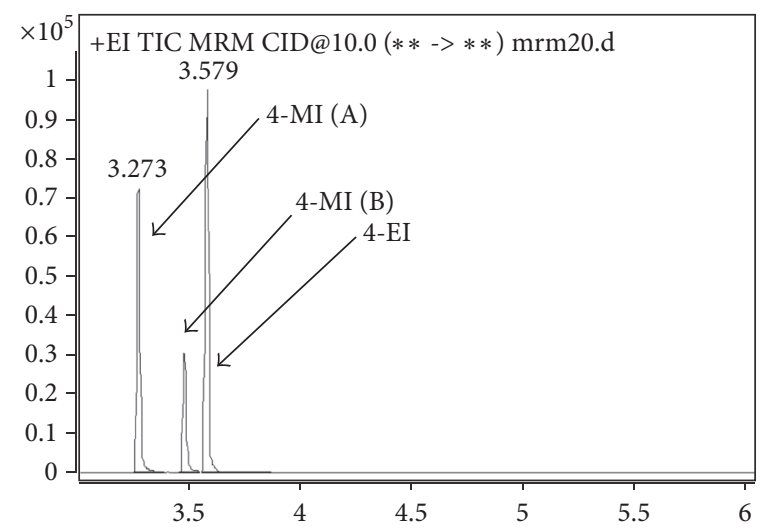

(c)

FIGURE 3: Chromatogram in SCAN (a), SIM mode (b), and MRM (c) of spiked caramel ammonia (40 $\mu \mathrm{g} \mathrm{mL} \mathrm{L}^{-1}$ of 4-MI (A and B) and $20 \mu \mathrm{g} \mathrm{mL}^{-1}$ of 2 -EI (internal standard)).

in triplicate usually below $15 \%$. No higher deviations were observed for intraday analyses. RSD values $<15 \%$ were also observed with higher number of replicates of a single sample $(n=7)$. The recovery level of spiked sample was evaluated for one concentration $\left(40 \mu \mathrm{g} \mathrm{mL}^{-1}\right)$ and it was $101 \%$. In present work LOD and LOQ were calculated by using the signalto-noise method. Noise before or after eluting peak was measured and, subsequently, the concentration of the analyte that would yield a signal equal to certain value of signal to noise ratio ( $\mathrm{S} / \mathrm{N}=3$ assumed in the work) is estimated [11]. LOQ was estimated as 2 LOD. In current work LOD and LOQ were $11.1 \mu \mathrm{g} \mathrm{kg}^{-1}$ and $24.7 \mu \mathrm{g} \mathrm{kg}^{-1}$, respectively, for MS/MS detection mode.

When 4-MeI is analyzed using ion pairing and IBCF derivatization method two peaks of the 4-MeI derivatives were obtained. They differed in retention times; however they share the same spectra with $\mathrm{m} / z 41$ as the base peak resulting from fission of $\mathrm{CH}_{3} \mathrm{CN}$ from imidazole ring, $\mathrm{m} / z$ 57 of all isobutyloxycarbonyl derivatives, and $m / z 182$ as the derivative molecular ion [5]. Chromatograms of ammonia caramel containing 4-MeI obtained in different operation mode of MS are shown on Figure 3.

As the method of 4-MeI in caramel and caramel containing food products require selective sample preparation, ion pair extraction with subsequent derivatization with IBCF was used. The method of extraction and derivatization in GC/MS based applications offers the highest selectivity and has been used in different applications (Table 1). LOD and LOQ values remained close to these in GC/MS methods used by Fernandes and Ferreira [5], Casal et al. [7], and Cunha et al. $[8,10]$. However, when experiments were run within this project on the same instrument (triple quadrupole) but ran in a single quadrupole SIM mode (first quadrupole set to transmission, collision gas switched off, and second quadrupole used for SIM) much higher LOD and LOQ values were obtained. Using the same method for $\mathrm{S} / \mathrm{N}$ calculation, LOD and LOQ values in SIM mode were $338 \mu \mathrm{g} \mathrm{kg}^{-1}$ and $\mathrm{LOQ}=675 \mu \mathrm{g} \mathrm{kg}^{-1}$, respectively, which makes it almost 30 times higher than the values obtained for MS/MS method using the same instrument. Assuming the sensitivity of triple quadrupole instrument may be lower than that of a single quadrupole (longer ion path, need for ion beam focusing) obtained results illustrate the advantage of MRM over SIM detection.

Elaborated method was used to quantify the amounts of 4-MeI in 7 different samples of ammonia caramel produced. Results are shown in Table 2. The diversity of results obtained for analyzed samples of caramel reflects the differences 
TABLE 1: Selected gas chromatographic methods used after extraction step, for the determination of 4-MeI in caramel colored food products.

\begin{tabular}{llccc}
\hline Matrix & Extraction method & LOD & LOQ & References \\
\hline Ammonia caramel & Ion-pair extraction & $5 \mu \mathrm{g} \mathrm{kg}^{-1}$ & $40 \mu \mathrm{g} \mathrm{k}^{-1}$ & {$[5]$} \\
Roasted coffee & Ion-pair extraction & $5 \mu \mathrm{g} \mathrm{kg}^{-1}$ & $40 \mu \mathrm{g} \mathrm{k}^{-1}$ & {$[7]$} \\
Soft drinks and dark beer & Ion-pair extraction & $0.6 \mu \mathrm{g} \mathrm{L}^{-1}$ & $2.2 \mu \mathrm{g} \mathrm{L}^{-1}$ & {$[10]$} \\
Cooked meat & Solution extraction & $25 \mu \mathrm{g} \mathrm{kg}^{-1}$ & $40 \mu \mathrm{g} \mathrm{k}^{-1}$ & {$[9]$} \\
Balsamic vinegar and processed sauces & Ion-pair extraction & $130 \mu \mathrm{g} \mathrm{kg}^{-1}$ & $250 \mu \mathrm{g} \mathrm{kg}^{-1}$ & {$[8]$} \\
Ammonia caramel & Ion-pair extraction & $11.1 \mu \mathrm{g} \mathrm{kg}^{-1}$ & $24.7 \mu \mathrm{gg}^{-1}$ & Current work \\
\hline
\end{tabular}

TABle 2: The content of 4-MeI in 7 different ammonia caramel samples produced in pilot scale.

\begin{tabular}{lccc}
\hline Sample Number & Mean value $\left[\mathrm{mg} \mathrm{kg}^{-1}\right]$ & SD & RSD [\%] \\
\hline 1 & 11.1 & 1.56 & 14.0 \\
2 & 6.47 & 0.34 & 5.25 \\
3 & 13.4 & 0.44 & 3.39 \\
4 & 8.34 & 0.89 & 10.7 \\
5 & 12.3 & 1.51 & 12.3 \\
6 & 10.4 & 1.10 & 10.6 \\
7 & 10.4 & 1.61 & 15.6 \\
\hline
\end{tabular}

SD: standard deviation; RSD: coefficient of variation.

in their manufacturing process. In all samples satisfactory reproducibility was achieved.

\section{Conclusion}

Described method, based on ion pairing and derivatization in sample preparation steps, followed by gas chromatography with tandem mass spectrometry was useful for determination of 4 -MeI in highly complex matrix, which is ammonia caramel. As the matrix contains numerous compounds that may interfere with 4-MeI, selective extraction, derivatization, and detection were required. The novelty of this study was the use of MS/MS for quantitation of 4-MeI. As tandem mass spectrometry virtually eliminates the influence of matrix, especially coelution of ions of the same $m / z$, (as may happen in SIM), by their subsequent fragmentation, it allows more reliable quantitation and improved $s / n$ ratio. The method proved to be more sensitive than SIM (determined on the same instrument, approximately 30 times) and was successfully applied to control levels of 4-MeI in ammonia caramel.

\section{Disclosure}

This work did not contain any studies with animal or human subjects.

\section{Conflicts of Interest}

All the authors declare that they have no conflicts of interest.

\section{References}

[1] K.-G. Lee, H. Jang, and T. Shibamoto, "Formation of carcinogenic 4(5)-methylimidazole in caramel model systems: a role of sulphite," Food Chemistry, vol. 136, no. 3-4, pp. 1165-1168, 2013.

[2] M. Hengel and T. Shibamoto, "Carcinogenic 4(5)-methylimidazole found in beverages, sauces, and caramel colors: chemical properties, analysis, and biological activities," Journal of Agricultural and Food Chemistry, vol. 61, no. 4, pp. 780-789, 2013.

[3] J.-K. Moon and T. Shibamoto, "Formation of carcinogenic 4(5)methylimidazole in maillard reaction systems," Journal of Agricultural and Food Chemistry, vol. 59, no. 2, pp. 615-618, 2011.

[4] H.-H. Lim and H.-S. Shin, "Simple determination of 4-methylimidazole in soft drinks by headspace SPME GC-MS," Chromatographia, vol. 76, no. 1-2, pp. 97-101, 2013.

[5] J. O. Fernandes and M. A. Ferreira, "Gas chromatographicmass spectrometric determination of 4-(5) methylimidazole in ammonia caramel colour using ion-pair extraction and derivatization with isobutylchloroformate," Journal of Chromatography A, vol. 786, no. 2, pp. 299-308, 1997.

[6] Commission Directive, "Commission directive laying down specific purity criteria concerning colours for use in foodstuffs, 2008/128/EC," December 2008, http://www.fao.org/faolex/results/ details/en/c/LEX-FAOC084282/.

[7] S. Casal, J. O. Fernandes, M. B. P. P. Oliveira, and M. A. Ferreira, "Gas chromatographic-mass spectrometric quantification of 4(5-)methylimidazole in roasted coffee after ion-pair extraction," Journal of Chromatography A, vol. 976, no. 1-2, pp. 285-291, 2002.

[8] C. Cunha, L. Senra, J. O. Fernandes, and S. C. Cunha, "Gas chromatography-mass spectrometry analysis of 4methylimidazole in balsamic vinegars and processed sauces," Food Analytical Methods, vol. 7, no. 7, pp. 1519-1525, 2014.

[9] F. Karim and J. S. Smith, "Detection and quantification of 4(5)methylimidazole in cooked meat," Journal of Food Science, vol. 80, no. 2, pp. T465-T471, 2015.

[10] S. C. Cunha, A. I. Barrado, M. A. Faria, and J. O. Fernandes, "Assessment of 4-(5-)methylimidazole in soft drinks and dark beer," Journal of Food Composition and Analysis, vol. 24, no. 4-5, pp. 609-614, 2011.

[11] A. Shrivastava and V. B. Gupta, "Methods for the determination of limit of detection and limit of quantitation of the analytical methods," Chronicles of Young Scientists, vol. 2, pp. 21-25, 2011.

\section{Funding}

The work was funded by Poznań University of Life Sciences, Project 508.752.00.0. 


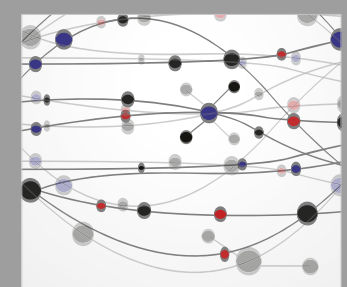

The Scientific World Journal
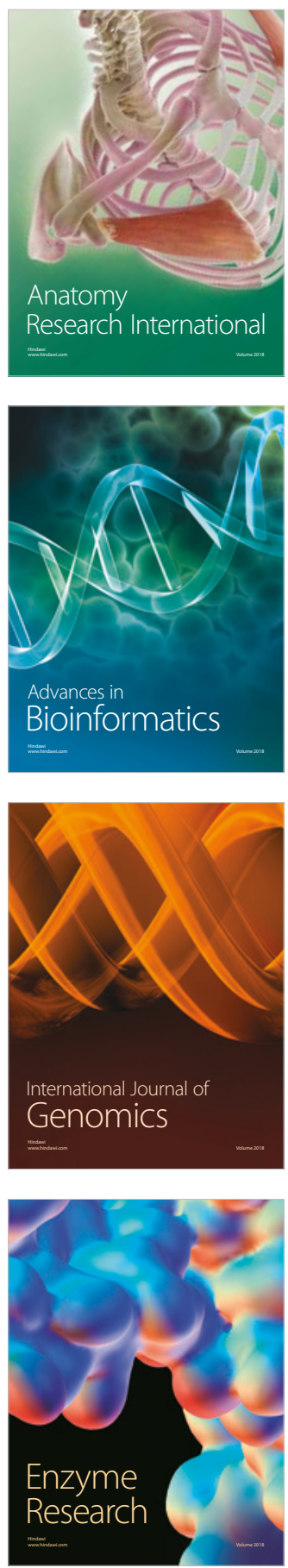
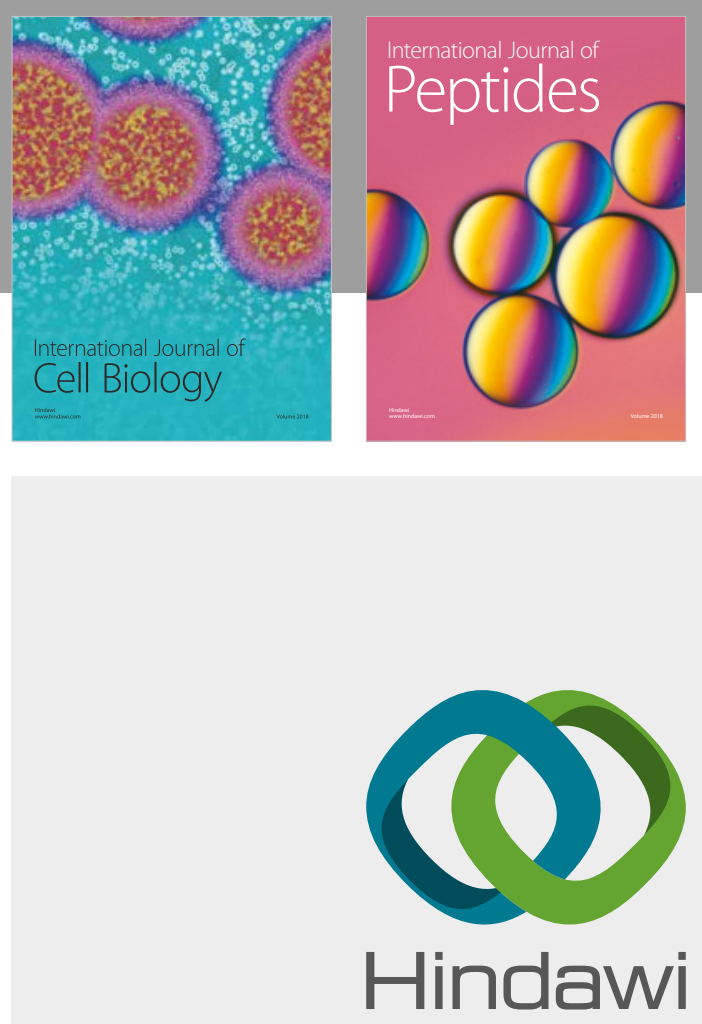

Submit your manuscripts at

www.hindawi.com
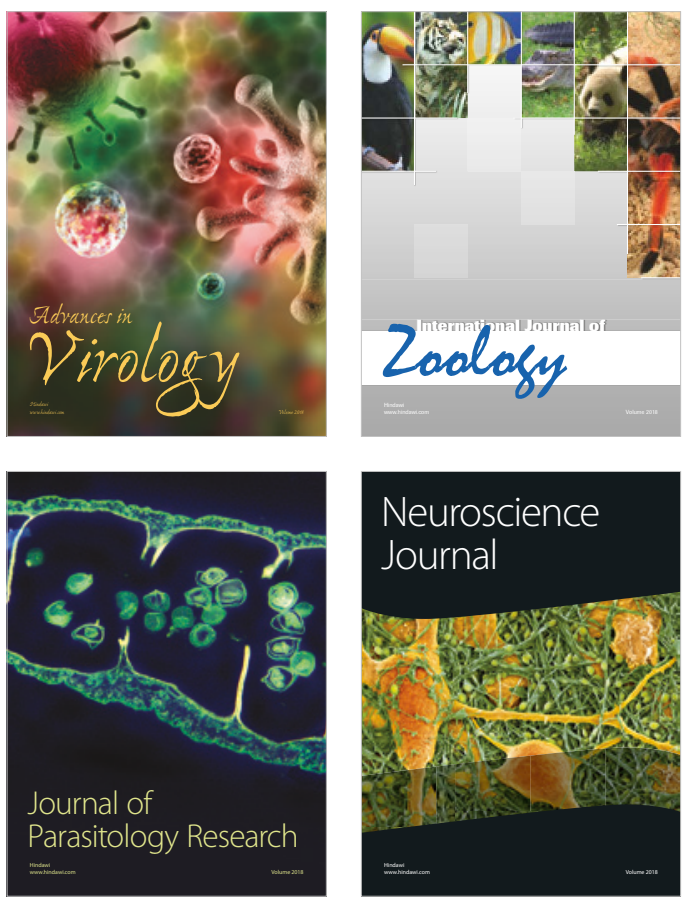
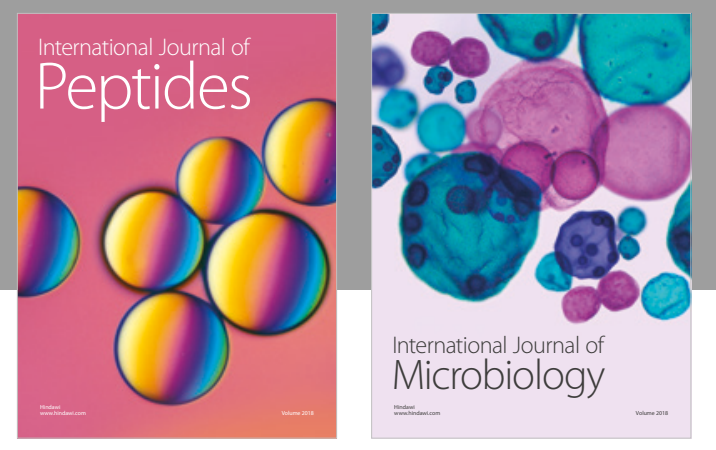

nternational Journal of Microbiology
Journal of
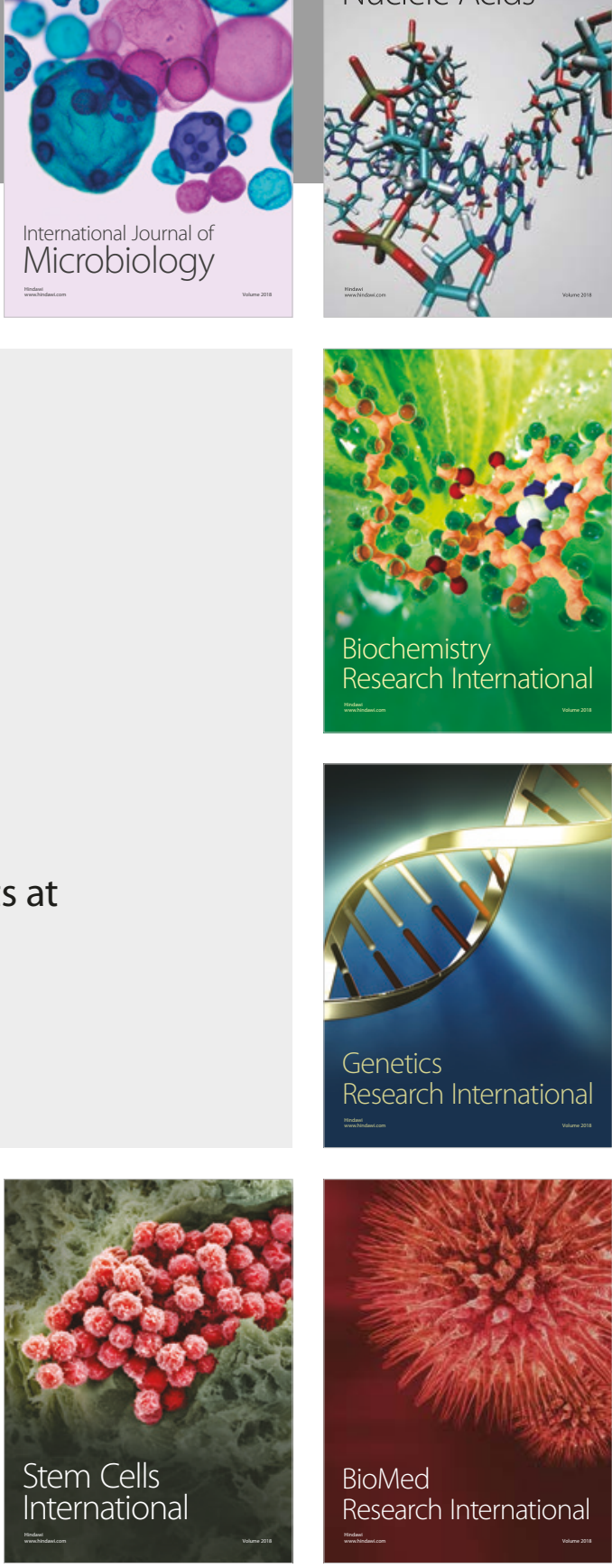
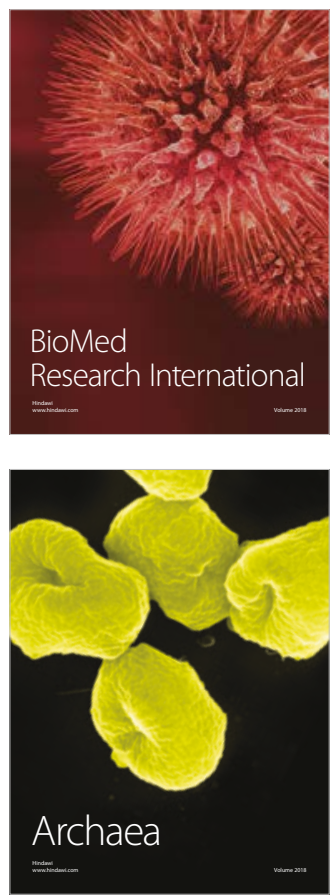